ISSN 1676-3742

\title{
O significado da Escritura para a fé católica
}

Maria de Lourdes Corrêa Lima

\section{Resumo}

A ênfase na leitura da Escritura dentro da grande Tradição parece por vezes indicar que a Escritura ocupa na fé católica um lugar de pouca relevância. A presente comunicação pretende colocar luz neste tema. Para tanto, percorre dois momentos, um histórico e outro filosófico. No primeiro, procura-se demonstrar, através de dados documentais, que a Igreja, em seu Magistério, dos inícios até hoje, reconheceu teórica e praticamente o valor da Sagrada Escritura. No segundo momento, a partir das reflexões de H.G. Gadamer, reflete-se sobre o conceito e o significado da "tradição", sob o ponto de vista filosófico e cultural, para, em seguida, aplicar estes dados à relação entre Escritura e Tradição, tal como concebida pela fé católica.

Palavras-chave: Relação Escritura - Tradição; Leitura da Escritura na Igreja Católica; Hermenêutica Bíblica.

\section{Résumé}

L'accent mis sur la lecture de l'Écriture dans la grande Tradition semble parfois indiquer que l'Écriture dans la foi catholique n'occupe pas une place de haute importance. Cette communication vise à mettre la lumière à ce sujet. 
À cette fin, traverse deux moments, un historique et autre philosophique. Dans le premier, on cherche à démontrer par des preuves documentaires, que l'Église dans son enseignement, dès le début jusqu'à aujourd'hui, à la fois théoriquement et pratiquement reconnut la valeur de l'Écriture. Dans le deuxième moment, à partir des réflexions de H.G. Gadamer, on réfléchit sur le concept et la signification du terme "tradition" dans le cadre philosophique et culturel, pour ensuite appliquer ces données à la relation entre l'Écriture et la Tradition, tel comme elle est conçue par la foi catholique.

Paroles clés: Relation Écriture - Tradition; Lecture de l'Écriture dans l’Église Catholique; Herméneutique de la Bible.

\section{Introdução}

Tratar do significado da Escritura para a fé católica é tocar em algo essencial para esta mesma fé. A história demonstra a importância que a Escritura sempre teve na formulação e na vivência da fé. Por outro lado, coloca-se a questão que a fé católica entende que a Escritura está indissoluvelmente unida à Tradição, de modo que é através de ambas (e não somente da Escritura) que se tem acesso à Palavra de Deus revelada. Isto se tornou ponto de discórdia particularmente na época da Reforma e perdura ainda hoje em grande parte, apesar da grande aproximação havida entre as Igrejas no tocante a este assunto.

Aqui procurar-se-á primeiramente evidenciar, através de algumas indicações históricas, como de fato a Escritura recebeu da Igreja total reverência e valorização. Em seguida, refletir-se-á sobre a importância da Escritura e seu relacionamento com a Tradição. Renuncia-se por princípio a uma abordagem dogmática, preferindo-se, em virtude do escopo de dialogar com outras confissões de fé, uma reflexão de cunho mais filosófico e histórico.

\section{A valorização da Escritura desde os primórdios da Igreja}

Desde os primeiros tempos, a Igreja demonstrou uma particular reverência pela Sagrada Escritura, como norma de fé e moral. Já nos primeiros escritos patrísticos, são abundantes as citações ou alusões a textos bíblicos (como, por exemplo, a Didaché, a carta de Clemente Romano aos Coríntios, as cartas de Inácio de Antioquia). Os grandes padres da Igreja, 
antes de fazerem tratados sobre dogmas, falaram da Sagrada Escritura e comentaram seus livros: à guisa de exemplo, Orígenes, Jerônimo, Ambrósio, Agostinho, Gregório Magno. É conhecida a frase de Jerônimo que, no prólogo ao livro de Isaías, afirma: "Ignorar as Escrituras é ignorar Cristo" ("IgnoratioenimScripturarumignoratio Christi est") ${ }^{1}$. Na época patrística, fazer teologia era de fato explicar a Escritura.

Em toda Antiguidade e Idade Média, a Escritura foi cultivada na liturgia, na oração, na pregação e catequese. Nos mosteiros, houve o grande trabalho de cópia de manuscritos bíblicos e se desenvolveu a leitura orante da Palavra. A própria arte era colocada a serviço da Escritura, através de afrescos, mosaicos, vitrais, baixos-relevos, etc, que ilustravam cenas bíblicas e serviam, para o povo, em sua grande maioria iletrado, como memória da palavra da Escritura.

É significativo ainda, por exemplo, que, no seu trabalho pioneiro de evangelização dos povos eslavos, em 885 Metódio tenha traduzido a Bíblia para o idioma destas nações. Para outros idiomas, outras traduções tinham sido realizadas já antes e continuaram também em épocas posteriores, com a finalidade de aproximar o povo em geral do texto sagrado. Em alemão, por exemplo, existe, no ano 748, o "Mateus de Mondseer". Do ano 830, a "Harmonia dos Evangelhos". Antes de 1022, os Salmos e os cânticos bíblicos. Durante a Idade Média, existiam 817 manuscritos em alemão, dos quais 43 são Bíblias inteiras, 599 são textos do Antigo Testamento (dos quais 342 traduções dos Salmos) e 165 do Novo Testamento (dos quais 34 só com os Evangelhos). Havia ainda a Bíblia pauperum (“Armenbibel”), que trazia textos em alemão, ou em latim e alemão, especialmente do Novo Testamento, mas também do Antigo, com ilustrações. No início, esta Bíblia pauperum fora pensada para o clero pobre que não podia ter uma Bíblia inteira (a imprensa ainda não fora inventada). Mais tarde, ela ficava nas Igrejas mais importantes, presa com uma corrente, para todos poderem consultá-la sem que fosse roubada. Em francês medieval são conhecidas muitas traduções parciais (Salmos, Apocalipse etc), especialmente a partir do ano $1200^{2}$.

Com o advento da imprensa (1450), do ano 1466 até 1522 já existem 14 edições impressas em alto alemão e 4 em holandês. Em francês, a primeira Bíblia impressa data do ano 1477/78 (em Lyon) e reproduz um texto do $13^{\circ}$ século, depois revisado e publicado em 1487.

\footnotetext{
${ }^{1}$ CCL (Corpus Christianorum, Series Latina) 73,1; PL 24,17.

${ }^{2}$ Cf. J. SCHMID - E. BEAUCAMP - J. KÜRZINGER, „Bibelübersetzungen“, in J. Höfer - K. Rahner (org.), Lexikon für Theologie und Kirche, II.Freiburg, Herder, 1958, 375-411, aqui, 401ss.
} 
Da parte do Magistério, foram emanados documentos que incentivavam a leitura e o estudo da Escritura. Já no Concílio de Vienne (França), em 1311, foi redigido um documento sobre o estudo das línguas bíblicas ${ }^{3}$. O Concílio de Trento, em 1546, promulgou um decreto sobre a leitura e a pregação onde incentiva o estudo e o ensino da Escritura nas igrejas, nos mosteiros e também nas escolas públicas ${ }^{4}$. Significativas são também as palavras de recomendação da leitura da Escritura por todos os fieis.

É certo que algumas vezes houve a proibição da leitura da Escritura. Mas essa medida era circunstanciada pela presença de heresias que, com interpretações parciais e, por vezes, também através de traduções feitas de modo a secundar suas teses, ameaçavam o pouco discernimento do povo simples. Os Papas Paulo IV (1559) e Pio IV (1564) proibiram a impressão e a posse, sem permissão do bispo, de traduções vernáculas da Bíblia, devido ao uso da Escritura feito por grupos que se opunham à fé católica. Isto não se deu por uma desvalorização da Escritura e uma supervalorização da Tradição, mas foi uma medida pastoral (e não doutrinária) que deve ser compreendida em suas circunstâncias concretas. Mais tarde, também o Papa Pio VIII, na encíclica "Traditihumiliati" (1829) fala contra a proliferação de traduções vernáculas tendenciosas 5 . Gregório XVI, na encíclica "Inter PraecipuasMachinationes" (1844) lembra a proibição de leitura de traduções vernáculas tendenciosas feita em tempos anteriores na França (sínodo de Toulouse, 1229), na Alemanha e na Espanha ${ }^{6}$.

${ }^{3}$ Cf. EnchiridionBiblicum. Documenti della Chiesa sulla Sacra Scrittura. Edizione bilingue. Bologna, Dehoniane, 1993 (abreviado EB), n. 41-43.

${ }^{4}$ Cf. EB 65-72.

${ }^{5}$ Cf. EB 74a.

${ }^{6}$ Cf. EB 74d: "Nequeenimignoratis, quanta veldiligentiavelsapientia opus sittransferendafideliter in aliam linguameloquiaDomini; ut nihilproindefaciliuscontingat, quam ut in eorundemversionibus per societates bíblicas multiplicatisgravissimiextotinterpretumvelimpdrudentiavel fraude inseranturerrores; quosipsa porro illarummultitudo et varietasdiuoccultat in perniciemmultorum ... permissa porro habeaturlectiovulgariumversionum, quaeab Apostólica Sede approbatae, aut cum annotationbusdesempisexsanctisEcclesiaePatribusvelexdoctiscatholicisque viris editaefuerint" (E vós, finalmente, bem sabeis quanto cuidado e sabedoria são necessários para uma fiel tradução das palavras do Senhor para outra língua; destarte, nada acontece mais facilmente do que aquilo que nas traduções, multiplicadas pelas Sociedades Bíblicas, haja gravíssimos erros, seja devido à incompetência [ou falta de cuidado - "imprudentia"] ou devido à fraude dos tantos tradutores; e é exatamente a multidão e a variedade de traduções que contribuem para que os erros fiquem ocultados para o grave dano de muitos ... Futuramente, somente sejam consideradas lícitas aquelas traduções na língua popular que forem aprovadas pela Sé apostólica ou editadas com anotações tiradas dos Padres da Igreja ou de homens doutos católicos). 
No final do século XIX, veio à luz o primeiro documento inteiramente dedicado a temas da Sagrada Escritura: a encíclica "Providentissimus Deus", de Leão XIII (1893)7 . O início do século XX viu a proliferação de medidas que favoreciam a leitura e o estudo da Sagrada Escritura. Em 1902, na carta apostólica "Vigilantiae", o mesmo Papa criava a Pontifícia Comissão Bíblica, para a promoção das ciências bíblicas ${ }^{8}$. Em 1909, na carta apostólica "VineaElecta", Pio X fundava o Pontifício Instituto Bíblico, para aprofundamento em alto nível dos estudos bíblicos 9 . Na primeira metade do século passado, documentos de Bento XV e Pio XII incentivaram a pesquisa bíblica ${ }^{10}$ e as numerosas realizações da Pontifícia Comissão Bíblica evidenciaram a atenção dada à Escritura. Todo este movimento culminou no Vaticano II, com a constituição Dei Verbum, que orienta as perspectivas e as atividades eclesiais em torno da Palavra de Deus e os três documentos especificamente bíblicos que depois dela surgiram: da parte da Pontifícia Comissão Bíblica, o documento "A Interpretação da Bíblia na Igreja” (1993) e "O povo hebraico e suas Sagradas Escrituras na Bíblia cristã" (2001); e a exortação "Verbum Domini", do Papa Bento XVI (2010), que recolheu os trabalhos do sínodo sobre a Palavra ocorrido em 2008.

Sem ser exaustiva, a apresentação acima evidencia a alta estima de que a Sagrada Escritura gozou, na fé católica, desde as suas origens até hoje.

\section{Em que sentido a Escritura é base para a fé}

A fé católica afirma a íntima relação da Escritura com a Tradição. Embora respeitando as peculiaridades das diversas confissões cristãs, atualmente muitas comunidades cristãs oriundas ou derivadas da Reforma estão também revalorizando a tradição na sua compreensão de fé. ${ }^{11}$

\footnotetext{
${ }^{7}$ Cf. EB 81-134.

${ }^{8}$ Cf. EB 137-148.

${ }^{9}$ Cf. EB 282-323.

${ }^{10}$ Particularmente as encíclicas "SpiritusParaclitus" (1920), "Divino AfflanteSpiritu” (1943) e "Humani Generis" (1950).

${ }^{11}$ Assim se expressa a estudiosa luterana E. PARMENTIER (cf. A Escritura viva. Interpretações cristãs da Bíblia. São Paulo, Loyola, 2009, p. 28): “A antiga controvérsia entre a Bíblia e a tradição revela-se hoje superada: as Igrejas concordam em falar de sua interação, embora a Bíblia conserve uma primazia absoluta sobre as decisões da Igreja". Sobre uma apresentação mais nuançada acerca da última afirmação da autora ("embora..."), ver abaixo.
} 


\section{a. Tradição: imobilismo versus dinamismo}

No mundo contemporâneo, porém, paira um grande descrédito no tocante à tradição ${ }^{12}$. A cultura atual procura relegar a tradição a um dado marginal ou mesmo nocivo. Pois identifica "tradição" com a ideia de inércia, paralisia, rejeição do novo, com falta de dinamismo e de abertura para o presente. Tal desqualificação foi levada adiante, por questões de ordem variada, sobretudo a partir do século XVI. Certamente contribuiu para isso o fato que a grande Tradição da Igreja, tal como era entendida desde os seus primórdios, tenha muitas vezes perdido importância frente às "tradições" ou costumes meramente humanos, que, em vez de expressar claramente a fé das origens, fixava-se sobre elementos fortemente marcados por traços culturais ou por perspectivas parciais e individualistas. Na época da Reforma, tal deterioração do conceito de Tradição (existente ao lado da manutenção da grande Tradição) levou à sua rejeição em bloco. Isto era movimentado também pela ideia de uma visão autônoma da fé, desvinculada da instituição eclesial (católica). De início, os reformadores não suprimiram o legado de fé dos primeiros concílios e dos autores mais antigos (os chamados Padres da Igreja). Porém, a Tradição perdeu, com o tempo, qualquer autoridade na formulação da fé, baseando-a unicamente na Escritura.

Tal visão foi reforçada com o Iluminismo, ao negar a validade da transmissão da fé e de qualquer dado advindo através das gerações. Unicamente valia o que caía sob o crivo da crítica pessoal racional; rejeitava-se totalmente qualquer "pré-compreensão" (dados recebidos e assimilados) dada de antemão. O dado tradicional era considerado "conservador", oposto ao progresso, defensor do status quo.

O romantismo rejeitou esta visão iluminista, mas não deu conta de oferecer uma proposta capaz de substituí-la. Por isso, quando retornou o interesse pelo passado, isso se deu simplesmente em sentido histórico racionalista, inclusive para demonstrar que as formulações de fé dependem da cultura e do momento em que apareceram, não podendo, portanto, ser normativas para todas as épocas. A tradição, assim, foi vista como algo concernente a uma fé não "iluminada".

Um exame sereno, no entanto, é capaz de perceber, na tradição, um elemento estrutural e constitutivo em todas as culturas. Estas, com efeito, constituem-se e perduram dentro de um dinamismo que é a um tempo manutenção de elementos essenciais e adaptação às novas realidades que, com o

${ }_{12}$ Nesta apresentação histórica, seguimos as grandes linhas apontadas por A.-M. PELLETIER, D’âgeenâgelesÉcritures. La Bible et l'herméneutique contemporaine. Bruxelles, Lessius, 2004, p. 115-118. 
desenrolar histórico, se apresentam. Tradição, assim, não se confunde com imobilismo, mas é movimento dinâmico de identidade que se expressa em formas novas, a partir dos desafios que surgem em cada época. Como para as culturas em geral, a tradição é também essencial para cada confissão de fé.

\title{
b. A contribuição da hermenêutica filosófica ${ }^{13}$
}

Nos últimos tempos, o filósofo H.-G. Gadamer retomou a questão da tradição e sua função na hermenêutica. Na obra Verdade e Método ${ }^{14}$, o autor trata desse assunto exaustivamente. Sua tese central é que a história da interpretação é princípio hermenêutico. $\mathrm{O}$ autor inicia analisando a noção de "pré-compreensão" que estava na raiz da crítica iluminista à tradição. Para Gadamer, a pré-compreensão não é de modo algum um elemento que prejudica a interpretação. Ao contrário, é necessário, pois o conhecimento se dá a partir do que já se tem e não a partir do nada.

\begin{abstract}
"Escutar a tradição e situar-se nela é o caminho para a verdade que se deve encontrar nas ciências do espírito. A própria crítica que fazemos à tradição, enquanto historiadores, acaba servindo ao objetivo de localizar-nos na autêntica tradição em que nos encontramos. O condicionamento, portanto, não prejudica o conhecimento histórico, sendo um momento da própria verdade. Precisa ser levado em conta se não quisermos agir arbitrariamente com relação a ele" $"$.
\end{abstract}

Nesse sentido, a tradição é uma realidade prévia na qual todos estão já inseridos de antemão e da qual ninguém se pode desligar completamente. Mesmo se negasse seus conteúdos, estaria afirmando sua realidade e entrando em diálogo com ela. Passado e presente estão intimamente imbricados, de forma que o homem atual vive da tradição e simultaneamente a constitui como legado para o futuro. Tradição não tem nada a ver, portanto, com paralisia no passado, conservação estagnante e contraposta à inovação e ao progresso. Ela pode ser entendida como uma "interpelação", que traz ao intérprete vozes do passado e lhe oferece dados.

"O primeiro elemento com que se inicia a compreensão é o fato de que algo nos interpela. É a primeira de todas as condições hermenêuticas"16.

\footnotetext{
${ }^{13}$ Cf., para este ponto, a obra de A.-M. PELLETIER, D’âge en âge les Écritures, p. 119-126.

${ }^{14}$ Cf. H.G. GADAMER, Verdade e Método, II. Petrópolis, Vozes, 2002.

${ }^{15}$ H.G. GADAMER, Verdade e Método, p. 53 (nº 40).

${ }^{16}$ H.G. GADAMER, Verdade e Método, p. 80 (n 64).
} 
“A transmissão e a tradição não conservam seu verdadeiro sentido quando se enrijecem no herdado, mas quando se prestam como interlocutor experiente e permanente no diálogo que nós mesmos somos. Ao responder-nos e ao suscitar assim novas perguntas demonstram sua própria realidade e sua vitalidade contagiante" ${ }^{17}$.

"A hermenêutica deve partir do fato de que quem quer compreender está ligado à coisa que vem à fala na tradição, mantendo ou adquirindo um vínculo com a tradição a partir de onde fala o texto transmitido. Por outro lado, a consciência hermenêutica sabe que não pode estar ligada a esta coisa, nos moldes de uma unanimidade inquestionável e óbvia, como no caso da continuidade ininterrupta de uma tradição. Dá-se realmente uma polaridade entre familiaridade e estranheza, sobre a qual baseia-se a tarefa da hermenêutica"18.

Isto significa que a tradição está em contínuo crescimento e transformação. De modo paralelo, as questões do presente levantam o interesse pelo passado, suas questões e respostas. A tradição faz parte da perspectiva histórica e cabe ao intérprete dela haurir os elementos que podem contribuir para o seu trabalho.

"O tempo não é primeiramente um abismo que se deve ultrapassar porque separa e distancia. É na verdade o fundamento sustentador do acontecer, onde se enraíza a compreensão atual. Desse modo, a distância temporal não é algo que deva ser superado. A pressuposição ingênua do historicismo era a exigência de se transferir para o espírito da época, de se pensar com os conceitos e representações da época e não com os próprios e, desse modo, forçar uma passagem para a objetividade histórica. Na verdade, o que importa é reconhecer a distância temporal como uma possibilidade positiva e produtiva da compreensão. Esta distância é preenchida pela continuidade da origem e da tradição, em cuja luz se nos mostra tudo que nos é transmitido" $"$.

Leitura e interpretação não são assim jamais individualistas, mas são entrada num movimento que precede o leitor e que continuará depois dele.

\footnotetext{
${ }^{17}$ H.G. GADAMER, Verdade e Método, p. 172 ( $\left.{ }^{\circ} 145\right)$.

${ }^{18}$ H.G. GADAMER, Verdade e Método, p. 79 (n 63).

${ }^{19}$ H.G. GADAMER, Verdade e Método, p. 79 (n 63).
} 
“... nas ciências do espírito é importante auscultar da tradição histórica não apenas a nós mesmos, do jeito que já nos conhecemos, mas também algo diferente: Vale a pena experimentar o impulso que ela nos dá e que nos faz ir além de nós mesmos" ${ }^{20}$.

\section{c. Aplicação à leitura bíblica}

O Cristianismo tem origem num dado histórico, a vida e a obra de Jesus de Nazaré, determinante para seus seguidores e concebido não como simples passado, mas como constitutivo para a fé cristã e sua expressão no mundo em cada época. Por isso, a ideia de tradição lhe é essencial. Para a fé cristã, a revelação de Deus brota do Evangelho, da mensagem de Jesus Cristo. Inclui também o primeiro Testamento, mas é determinada pela mensagem de Jesus, que o ratificou e, segundo a compreensão cristã, o levou à plenitude. A mensagem de Jesus foi primeiramente pregada e vivida (costumes, moral, liturgia...) pelos apóstolos e pelas primeiras comunidades cristãs. A pregação e vivência dos cristãos das origens formam um todo de fé que faz parte da essência do Cristianismo: é a Tradição fundante, que tem origem em Jesus e é vivida e transmitida pelas primeiríssimas gerações; por isso é chamada tradição divino-apostólica ${ }^{21}$. Aos poucos essa pregação e vivência foram sendo postas por escrito, constituindo o que será depois o Novo Testamento. $\mathrm{O}$ primeiro Testamento foi assumido, como já para o próprio Jesus, como parte das Escrituras e lido então em chave cristã. Desse modo, a Escritura surge da Tradição e é definida em seus limites por esta mesma Tradição. A Tradição acompanha a formulação da Escritura e a autentica.

Por outro lado, o evangelho de Jesus (sua mensagem, não os "evangelhos" escritos) é capaz de alcançar toda a história a partir do testemunho apostólico passado adiante e sempre de novo retransmitido. Essa transmissão se dá numa dinâmica que é a um tempo conservação da identidade fundante e tematizações novas desta mesma identidade, sua explicitação, diante das demandas e necessidades de cada época e cultura. Assim, a mesma mensagem das origens desdobra suas virtualidades a partir das questões, das interrogações e desafios das diversas gerações. É o que se poderia chamar de Tradição conseqüente, que segue temporalmente os tempos dos primórdios.

\footnotetext{
${ }^{20}$ H.G. GADAMER, Verdade e Método, p. 56 (n 40).

${ }^{21}$ Cf. P. LENGSFELD, “Tradição e Sagrada Escritura”, in J. Feiner - M. Löhrer, MysteriumSalutis, I/2. Petrópolis, Vozes, 1971, p. 228.
} 
Com o distanciamento temporal da comunidade eclesial das origens, a Escritura é lida num processo de contínua interpretação e atualização. Sem esta dinâmica, a Escritura se tornaria um livro morto, um documento do passado, incapaz de falar para outras épocas. É graças a esta tradição viva que a Escritura é realmente palavra de Deus endereçada a todos os homens (em todas as épocas e culturas).

$\mathrm{Na}$ Igreja dos primórdios, a leitura da Escritura se fazia tendo em conta, como algo natural, a tradição, ou seja, a compreensão da mesma pelas gerações anteriores. Tal modo de ler não era uma completa novidade, mas continuava o que já se fazia na comunidade judaica (e que continuou a ser feito posteriormente no seio do Judaísmo): a tradição escrita (Tenak) era acompanhada da tradição oral (o ensinamento e interpretação dos mestres, posteriormente também postos por escrito). A partir dessa visão, interpretar um texto não se limitava a explicá-lo em seu momento de origem, mas significava simultaneamente torná-lo palavra viva para a geração atual e a percebê-lo dentro da comunhão diacrônica dos fieis. Dessa forma, a leitura da Bíblia na Igreja é sempre interpretação e, ao mesmo tempo, exercício da razão (que escuta as interpelações de cada época) em união com a memória de fé. Esta tem por finalidade garantir a identidade da mensagem de Jesus Cristo em sua explicitação histórica e cultural.

Nesse sentido é significativo o ensinamento do último concílio ecumênico, o Vaticano II. No documento Dei Verbum, sobre a Revelação divina, fala-se tanto da Escritura como da Tradição como palavra de Deus. O n. 9 diz que "a sagrada Tradição transmite integralmente a palavra de Deus". O n. 10 menciona a "Palavra de Deus escrita ou transmitida" ("Verbum Dei scriptumveltraditum"). O n. 21 afirma que "as divinas Escrituras ... comunicam imutavelmente a palavra do próprio Deus ("verbum ipsius Dei"; cf. $D V$, n. 24). E no n. 9 é de grande alcance a distinção feita: não se diz que a Escritura é Palavra de Deus, mas que ela é "o falar de Deus enquanto, sob o sopro do divino Espírito, é consignado por escrito" (Sacra Scriptura est locutio Dei, quatenus, divino afflanteSpiritu, scriptoconsignatur". Evita-se assim a identificação pura e simples da Escritura com a palavra de Deus; e, simultaneamente, dá-se à Escritura um sentido dinâmico: é Deus no ato de falar no presente ("consignatur") 22 .

\footnotetext{
${ }^{22}$ Cf. A. VANHOYE, "La parola di Dio nella vita della Chiesa. La recezione della 'Dei Verbum", in R. Fisichella (org.), Il Concilio Vaticano II. Recezione e attualità alla luce del Giubileo. Milano, San Paolo, 2000, p. 29-30.
} 
Certamente, confiada a seres humanos falíveis, a grande Tradição pôde, durante as gerações, não ser anunciada e vivenciada em toda a sua força, mas compreendida e aplicada de modo a perder sua vivacidade, tornando-se um conjunto de verdades estagnado, fixado em circunstâncias passadas (a tradição "tradicionalista"). Ou então pôde perder espaço para tradições circunstanciadas, que não representavam adequadamente a Tradição divinoapostólica. As questões, no tempo da Reforma, sobre o valor da Tradição giraram grandemente em torno dessas caricaturas que, com o passar do tempo, foram sendo criadas. Da possibilidade dessas desinterpretações surge a necessidade de critérios, que, pela própria natureza das coisas consistem na homogeneidade com a Tradição fundante e na homogeneidade com a Sagrada Escritura, expressão escrita desta Tradição.

A questão que se coloca, primeiramente, é como comprovar a homogeneidade com a Tradição fundante. Em termos práticos, tal comprovação torna-se difícil, pois esta Tradição encontra-se esparsa. Nesse sentido, a Escritura, como texto sacralizado, é ponto referencial seguro, de modo que se poderia falar de uma "suficiência da Escritura" 23 . A Escritura, porém, não como livro a se, mas compreendida e interpretada de tal modo que seja capaz de "falar" à Igreja por entrar na dinâmica da Tradição viva. Por ser inspirada diretamente por Deus e ser um testemunho escrito definitivo (aspecto canônico), a Escritura apresenta um aspecto de superioridade frente à Tradição. De outro lado, apresenta também um aspecto de inferioridade, enquanto tem necessidade da Tradição para não se tornar um livro morto ${ }^{24}$.

Em segundo lugar, coloca-se a comprovação da homogeneidade com a Sagrada Escritura. Muitas vezes levanta-se o tema de que a Igreja formulou doutrinas que não se encontram na Escritura. Interessante é, todavia, notar que todas as decisões dogmáticas vinculantes da Igreja apelam ao testemunho bíblico. A dificuldade de se estabelecer um nexo imediato, por vezes, entre a verdade doutrinária e a Escritura remete, em última instância, a uma questão hermenêutica, qual seja, a da suficiência de nosso (atual) conhecimento do texto bíblico. Não significa, portanto, a existência de uma heterogeneidade entre dogma e Escritura, mas, antes, a incapacidade (atual, possivelmente vencível com o desenvolvimento dos estudos bíblicos e das ciências da interpretação aplicadas à Sagrada Escritura) de interpretarmos os textos em todas as suas potencialidades de sentido.

${ }^{23}$ Cf. P. LENGSFELD, “Tradição e Sagrada Escritura”, p. 236.

${ }^{24}$ Cf. A. VANHOYE, "La parola di Dio nella vita della Chiesa”, p. 33. 
Confirma-se assim que a Escritura não pode ser isolada da Tradição, de um lado, e que a Tradição não o pode em relação à Escritura. Escritura e Tradição não são dois universos fechados em si, completos, isolados, sendo impossível sua inter-comunicação. O problema do relacionamento entre ambas surge quando se reduz a questão a um problema de conteúdo, o que não é senão um aspecto entre muitos. Para bem empostar o tema, é necessário considerar o que foi explanado acima, ou seja: - o liame natural que está na origem tanto da Escritura quanto da Tradição; - que ambas expressam o mesmo evangelho de Jesus Cristo; - e o caráter histórico, dinâmico, que está incluído no processo de transmitir, de geração em geração, a fé. Ambas Escritura e Tradição - (e não só a Escritura) são expressão da Palavra de Deus.

\section{Conclusão}

A Escritura é base de fé para a Igreja Católica e é venerada como meio privilegiado de acesso à Revelação. Sua leitura na comunidade eclesial supõe sempre sua inserção numa compreensão de fé que é anterior à própria Escritura, que lhe deu origem e finalmente a acompanha. Como a Tradição, no período fundante, deu origem aos textos sagrados pela inspiração do Espírito Santo, assim, nas fases sucessivas da história ela deve atualizar a Escritura também sob a assistência do mesmo Espírito. Assim se pode compreender sua mensagem para o tempo atual e torná-la operante. A grande Tradição é, dessa maneira, a pré-compreensão adequada para a leitura dos textos bíblicos. Pelo fato de não ser Escritura, mas ser viva, dinâmica, cabe, frente à Tradição, o discernimento permanente em vista de ela se manter fiel à sua origem dentro do dinamismo histórico.

\section{Referências Bibliográficas}

Corpus Christianorum. Series Latina, 24. Turnholti: Brepols, 1967.

Enchiridion Biblicum. Documenti della Chiesa sulla Sacra Scrittura. Edizione bilingue. Bologna: Dehoniane, 1993.

GADAMER, H.G. Verdade e Método, II. Petrópolis: Vozes, 2002.

LENGSFELD, P. “Tradição e Sagrada Escritura”. In J. Feiner - M. Löhrer (orgs), Mysterium Salutis, I/2. Petrópolis: Vozes, 1971.

PARMENTIER, E. A Escritura viva. Interpretações cristãs da Bíblia. São Paulo: Loyola, 2009. 
PELLETIER, A.-M. D'âge en âge les Écritures. La Bible et l'herméneutique contemporaine. Bruxelles : Lessius, 2004.

SCHMID, J. - BEAUCAMP, E. - KÜRZINGER, J. "Bibelübersetzungen", in J. Höfer - K. Rahner (orgs), Lexikon für Theologie und Kirche, II. Freiburg: Herder, 1958, 375-411.

VANHOYE, A. "La parola di Dio nella vita della Chiesa. La recezione della 'Dei Verbum'”. In R. Fisichella (org.), Il Concilio Vaticano II. Recezione e attualità alla luce del Giubileo. Milano: San Paolo, 2000.

\section{Maria de Lourdes Corrêa Lima}

Doutora em Teologia (Bíblica) pela Pontificia Università Gregoriana Professora de Sagrada Escritura da PUC-Rio e do Instituto Superior de Teologia da Arquidiocese do Rio de Janeiro

Artigo Recebido em 15/08/2011 Artigo Aprovado em 20/10/2011 